\title{
CHANGES IN THE BLOOD-TESTIS BARRIER OF THE GUINEA-PIG IN RELATION TO HISTOLOGICAL DAMAGE FOLLOWING ISO-IMMUNIZATION WITH TESTIS
}

\author{
M. H. JOHNSON \\ Department of Physiology, Dowening Street, Cambridge
}

(Received 5th May 1969)

\begin{abstract}
Summary. Immunological damage induced by iso-immunization of guinea-pigs with testis in adjuvant is most readily observed in the rete testis and vasa efferentia and is less frequently present in the testis and epididymis. Possible reasons for the greater vulnerability of the rete testis and vasa efferentia are discussed. The testis shows interstitial inflammation and an invasion of tubules by eosinophils and mononuclear cells. The tubular barrier to acriflavine, and possibly also to $\gamma$-globulin, partially breaks down during the invasive phase of initial damage but is restored before normal spermatogenesis is re-established. It is suggested that the occurrence of testicular damage is dependent upon the immune response, of whatever type(s), overcoming the protective effect of the blood-testis barrier.
\end{abstract}

\section{INTRODUCTION}

It is now well established by many authors that iso- or auto-immunization of the guinea-pig by testis or spermatozoa can lead to testicular damage which results from a specific immune response to sperm antigens (Freund, Lipton \& Thompson, 1953, 1955; Voisin, Toullet \& Maurer, 1958; Bishop, 1961; Katsh \& Katsh, 1961; Chutna \& Rychlikova, 1964; Bishop \& Carlson, 1965; Brown, Glynn \& Holborow, 1963, 1967; Brown, Holborow \& Glynn, 1965; Toullet, 1965; Voisin \& Toullet, 1968). It has been widely assumed that the testicular damage was mediated by immune cells. This assumption was made for four reasons, none of which is very convincing. (1) Complete adjuvant was found necessary to elicit damage and adjuvant boosts the delayed-hypersensitivity component of the immune response. In fact, damage can be induced without adjuvant (Bishop, 1961 ; Johnson, personal observation). Adjuvant also affects the type and sequence of antibody production and provides a general stimulation of all types of immune response (Bloch, Kourilsky, Ovary \& Benacerraf, 1963; Jonas, Gurner, Nelson \& Coombs, 1965). (2) The testicular damage has shown a better correlation with the delayed-hypersensitivity response than with the titre or presence of antibodies. In few published studies 
is there any complete correlation of damage with the delayed-hypersensitivity response, and most authors have not examined all types of antibody response. The most detailed study is that of Voisin \& Toullet (1968) who used isolated auto-antigens and found that of those males showing aspermatogenesis, $9 \%$ had a delayed-hypersensitivity response alone, $67 \%$ had a delayed-hypersensitivity response and a humoral response, and $26 \%$ had a humoral response alone. (3) Aspermatogenesis has been transferred by immune cells but not by serum antibody (Laurence, 1962; Stone, Lerner \& Goode, 1968). The use of cell transfer as unequivocal proof of a cell-mediated damage alone is open to doubt. Dangers arise from the transfer of small quantities of antigen in a highly immunogenic form (Askonas \& Rhodes, 1965a,b), from the transfer of antibody cytophilic for the transferred cells (Jonas et al., 1965), and from the transfer of specific immune cells capable of synthesizing antibodies in the host. Rigorous controls are therefore necessary before direct damage by transferred cells can be claimed convincingly. (4) Some authors have described a histological picture with massive cellular involvement (Waksman, 1959). Other workers fail to report invasion of immune cells at any stage in the induction of aspermatogenesis (Brown et al., 1967). Mononuclear and polymorphonuclear cells may occur at sites of antigenantibody interaction or non-specific inflammation, and the mere presence of leucocytes at a lesion is insufficient evidence for damage mediated solely by a delayed-type hypersensitivity mechanism.

Brown et al. (1967) have claimed that both cellular and humoral responses are necessary for aspermatogenesis, and the results of Voisin \& Toullet (1968) also suggest a rôle for antibody. Under normal conditions, the immunoglobulin content of the ram testis tubule fluid, collected by cannulating the rete testis, is only $0.2 \%$ that of serum (Johnson \& Setchell, 1968). If antibodies to spermatozoa are to play a rôle in producing aspermatogenesis, either the efficiency with which the blood-testis barrier excludes antibody is reduced, or the antibodies must be very potent or selectively transferred into the tubule over other antibodies.

The blood-testis barrier also excludes dyes, such as acriflavine, from the tubules and changes in the testicular distribution of this dye could give an indication of changes in the efficiency of the blood-testis barrier. This paper describes the distribution of the dye in relation to the histological changes in the testis following iso-immunization with testis.

\section{MATERIALS AND METHODS}

\section{Induction of aspermatogenesis by iso-immunization}

Fifty, Duncan-Hartley, male guinea-pigs weighing 500 to $700 \mathrm{~g}$ were injected with 50 or $100 \mathrm{mg}$ of isologous testis homogenate in complete Freund's adjuvant at a minimum of three sites intradermally in the suprascapular skin. A similar booster dose was given at Day 12 or Day 14. Testes were removed at intervals between Day 7 and Day 70 . Five animals were injected with adjuvant alone and five others with homogenates in adjuvant of guinea-pig brain, spleen, liver, kidney or muscle.

Testes and epididymides were fixed in 'Susa', and sections were stained with 
haematoxylin and eosin. Serial sections were cut at 25 to $35 \mu$ and the stages of spermatogenesis were scored as follows:

Stage 1. Spermatogonia type A, resting primary spermatocyte, pachytene primary spermatocyte, pale round spermatid.

Stage 2. Spermatogonia type A, leptotone primary spermatocyte, pachytene primary spermatocyte, oval spermatid.

Stage 3. Spermatogonia type A, leptotene primary spermatocyte, pachytene primary spermatocyte, elongated spermatid.

Stage 4. Spermatogonia type A, zygotene primary spermatocyte, dividing and secondary spermatocytes, elongated spermatid.

Stage 5. Spermatogonia type A, intermediate spermatogonia, pachytene primary spermatocyte, dark round spermatid, deeply embedded long spermatid.

Stage 6. Spermatogonia type A, intermediate spermatogonia, pachytene primary spermatocyte, dark round spermatid, embedded long spermatid.

Stage 7. Spermatogonia types A and B, pachytene primary spermatocyte, dark round spermatid, luminally embedded long spermatids.

Stage 8. Spermatogonia types $\mathrm{A}$ and $\mathrm{B}$, pachytene primary spermatocyte, pale round spermatid, luminal and free spermatozoa.

\section{Acriflavine permeability}

Iso-immunized animals were injected subcutaneously with a $2 \%$ acriflavine solution $(20 \mathrm{mg} / \mathrm{kg}) 5 \mathrm{hr}$ before being killed. Blocks of fresh testis were snapfrozen in Arcton (ICI) cooled in liquid nitrogen, and freeze-dried. The blocks were then vacuum-embedded and sections were cut and mounted in xylol and observed under phase and dark-field illumination on the Zeiss photomicroscope (super pressure mercury vapour lamp HB 200W, exciter filters BG 3 and BG 38, barrier filter 47). Acriflavine normally stains vascular nuclei strongly and interstitial nuclei weakly, and fails to stain intratubular nuclei (Kormano, 1967; Johnson, 1969) and differences from this staining pattern following iso-immunization with testis were scored.

Positive controls were (1) testes from 2-day-old guinea-pigs in which the acriflavine barrier is not fully developed (Pl. 1, Fig. 1), and (2) a testis injected with a $0.1 \%$ solution of acriflavine 15 min before the animal was killed (Pl. 1 , Fig. 2).

Negative controls were (1) testis from immunized animals with no acriflavine, and (2) testis from non-immunized animals with acriflavine.

\section{Immunological tests on animals iso-immunized with testis}

Immune fluorescence. Small pieces of testis from immunized animals were fixed, embedded and sectioned according to the technique of Sainte-Marie (1962). The sections were washed in buffer and treated with fluorescein-conjugated anti-guinea-pig $\gamma$-globulin. After further washing, sections were viewed under fluorescence on the Zeiss photomicroscope.

Passive cutaneous anaphylaxis. Intradermal injections $(0.1 \mathrm{ml})$ of test and control sera were made into the bellies of $250 \mathrm{~g}$ albino guinea-pigs. After $5 \mathrm{hr}, 0.5 \mathrm{ml}$ 
of the supernate of an homogenate of guinea-pig testis in saline was injected intravenously, followed by $0.5 \mathrm{ml}$ of $1 \%$ Geigy Blue B.

Cytotoxic antibody. Dilutions of sera were made in diluent (Medium 199: Hank's: $5 \%$ foetal calf serum: phosphate buffer, $\mathrm{pH} \mathrm{7.2)} \mathrm{and} 2$ vols added to I vol of complement ( $1 / 5$ fresh guinea-pig serum) and 1 vol of spermatozoa $\left(2 \times 10^{6} / \mathrm{ml}\right)$. Tubes were incubated for $30 \mathrm{~min}$ at $37^{\circ} \mathrm{G}$, and sperm death evaluated by eosin penetration.

Skin tests. An injection $(0.1 \mathrm{ml})$ of the supernate of testis homogenate in saline was given intradermally into the belly of immunized and control animals and scored at 2, 8 and $24 \mathrm{hr}$ for erythema and induration.

\section{RESULTS}

Patterns of histological damage to testis, acriflavine permeability and immune response In control animals, there was no visible damage at any point in the tract.

\section{EXPLANATION OF PLATES}

\section{PLATE 1}

FIG. 1. Testis from 2-day-old guinea-pig injected subcutaneously $5 \mathrm{hr}$ previously with acriflavine. Intratubular and extratubular nuclei stain $(\times 360)$.

Fic. 2. Mature testis following intratesticular injection of acriflavine. Nuclei are intratubular and stain vividly $(\times 360)$.

Fig. 3. Testis from guinea-pig immunized 18 days previously with testis, and injected $5 \mathrm{hr}$ previously with acriflavine. Note the staining of intratubular nuclei, which does not occur in normal adult testes $(\times 360)$.

Fig. 4. Testis from mature guinea-pig immunized 5 weeks previously with testis, and injected $5 \mathrm{hr}$ previously with acriflavine. Arrows indicate stained interstitial nuclei; lines indicate position of unstained intratubular nuclei $(\times 145)$.

FIG. 5. Phase picture of same field. Arrows and lines to corresponding nuclei $(\times 145)$.

FIG. 6. Section from the testis shown in Fig. 3 treated directly with fluorescent-labelled anti$\gamma$-globulin. Note central fluorescence $(\times 360)$.

Fig. 7. Section from an undamaged testis treated with labelled anti- $\gamma$-globulin. No staining in centre of tubule $(\times 360)$.

\section{PLATE 2}

FIG. 8. Massive invasion of rete testis tubules and interstitium by leucocytes $(\times 90)$.

Fig. 9. High power view of invaded rete testis tubule. Note spermatozoa phagocytosed by mononuclear cells (arrowed) $(\times 900)$.

Fig. 10. Invasion of vasa efferentia. Note mononuclear cells and polymorphonuclear cells $(\times 320)$.

FrG. 11. Invading cells in lumen only of caput epididymidis $(\times 145)$.

FIG. 12. Massive tubular and interstitial invasion of epididymis by leucocytes $(x 145)$.

Frg. 13. Distended seminiferous tubules. Note distinctness of Sertoli cells and associated spermatogenic cells and presence of mature spermatozoa in centre of lumen $(\times 90)$.

\section{PLATE 3}

FIG. 14. Seminiferous tubule invaded by mass of leucocytes $(\times 180)$.

FrG. 15. Eosinophil in seminiferous tubule (arrowed) $(x 1600)$.

Fig. 16. Phagocytic mononuclear cells in seminiferous tubule $(\times 720)$.

Frg. 17. Eosinophil crossing basement membrane of seminiferous tubule (arrow to granules and nucleus; $\mathrm{T}=$ intratubular regions of adjacent tubules; $\mathrm{I}=$ triangular area of interstitial tissue $)(\times 2500)$. 
PI.11\%
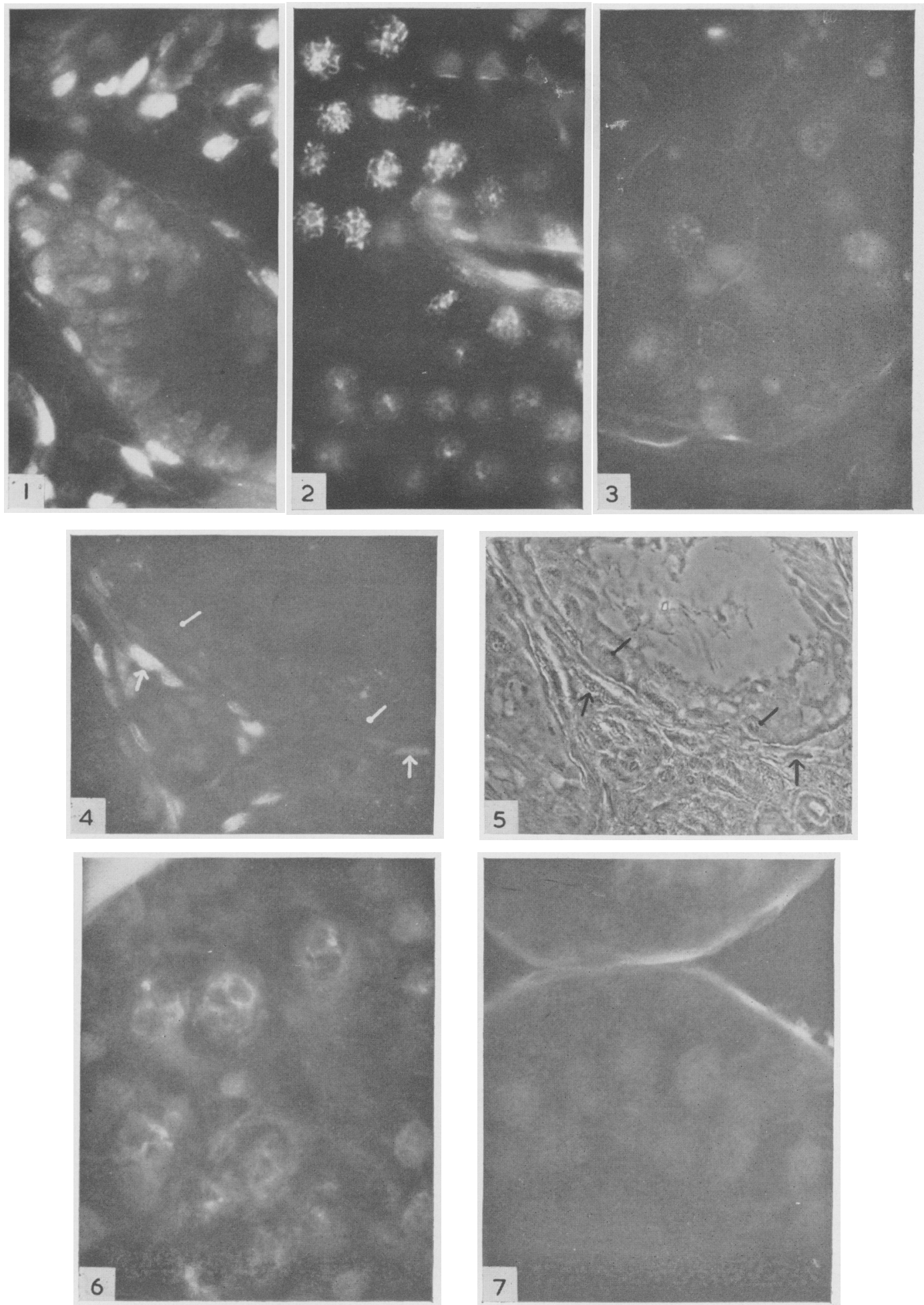

Hering the 1.:- 
PIAATE 2
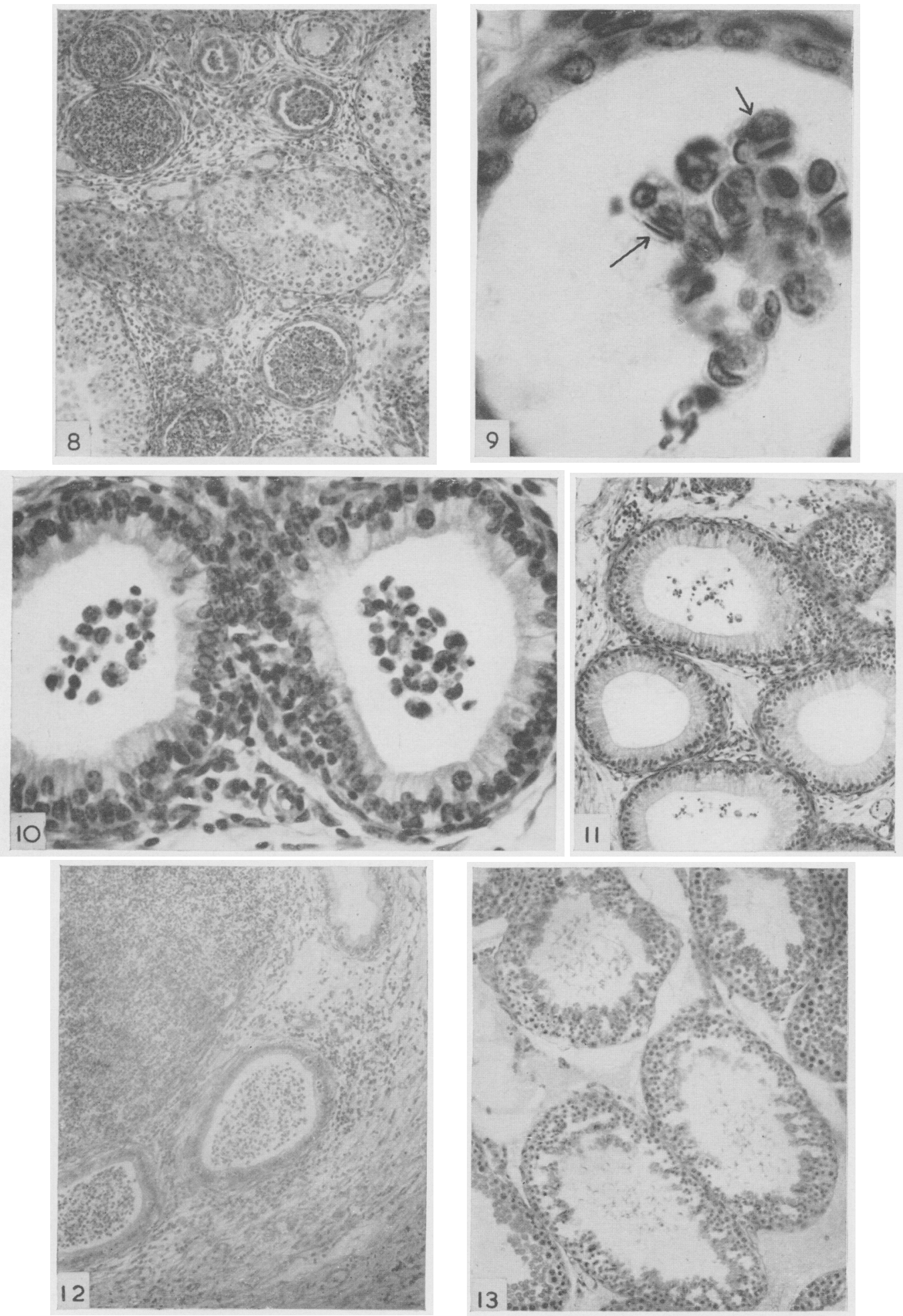
PLATE 3
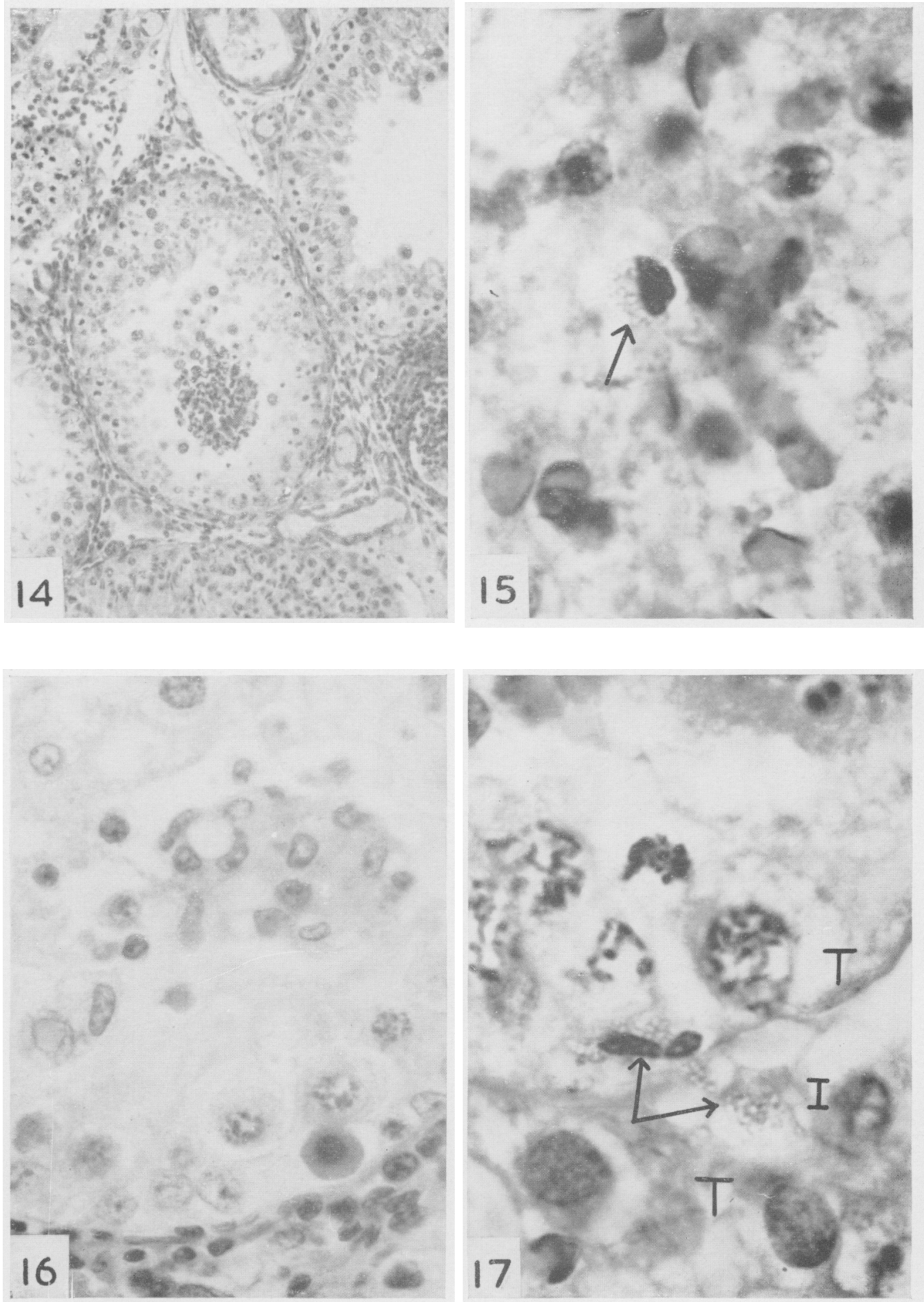
In animals iso-immunized with testis, three patterns of damage were seen.

(a) No observable damage at any point in the tract. A few animals did not differ from the controls, especially those animals injected with $50 \mathrm{mg}$ of testis in the early stages after immunization (Days 7 to 14). This was despite the presence of a positive immediate and delayed skin response, and of cytotoxic and anaphylactic antibodies. The testes showing this pattern had no intratubular, and weak interstitial, staining of nuclei with acriflavine, and thus did not differ from negative controls (Group 2).

(b) Signs of extensive damage, but no leucocytic invasion. Excurrent ducts were devoid of spermatozoa. Testes showed complete or partial destruction of the tubular contents, with the exception of Sertoli cells. Severely damaged tubules were usually of smaller diameter. Some normal tubules were present in a few testes. Interstitial tissue showed fibrosis and occasional foci of lymphocytes. This is the typical picture described by most workers and occurred in all animals examined more than 30 days after the initial immunization and in a few examined earlier. Testes from these animals showed vivid vascular and interstitial staining with acriflavine but intratubular nuclei only a few microns away failed to stain (PI. 1, Figs. 4 and 5). All these animals showed weak delayed hypersensitivity responses, twelve out of twenty possessed anaphylactic antibodies and sixteen out of twenty possessed cytotoxic antibodies. There was no correlation between the presence or titre of any one type of immune response and the degree of damage.

(c) Signs of massive local inflammation and cellular infiltration. The rete testis and vasa efferentia of these testes always showed severe damage, even when the testis and epididymis were unaffected. The ducts and surrounding interstitium were invaded by mononuclear cells, eosinophils and neutrophils, and phagocytosis of spermatozoa was occurring (PI. 2, Figs. 8, 9 and 10).

The epididymis was also inflamed in some animals, and this was more common in the small caput epididymidis than in the cauda. In the epididymides of many animals, the interstitial tissue and duct epithelium were not affected, suggesting that the phagocytosing cells had migrated down, rather than through, the duct (PI. 2, Fig. 11). Large granulomata were present in some epididymides (Pl. 2, Fig. 12).

The testis was the region least affected. The interstitial tissue near the rete testis was heavily invaded by eosinophils, mononuclear cells and neutrophils. In areas more remote from the rete, the intensity of inflammation decreased and neutrophils were absent. Fibroplasia occurred interstitially. Tubule morphology was variable and could be divided into three categories:

(i) apparently undamaged with or without surrounding inflammation,

(ii) with normal histology, but greatly distended and frequently with a central mass of spermatozoa. Presumably, outflow of the testicular fluid at the rete was blocked (Pl. 2, Fig. 13), and

(iii) damaged tubules. Invading cells were present in many tubules. Near the rete testis, mononuclear cell, eosinophil and neutrophil masses were present (Pl. 3, Fig. 14) but further from the rete, only eosinophils and mononuclear cells were observed (Pl. 3, Figs. 15 and 16). In Plate 3, Fig. 17, an eosinophil is shown 'crossing' the basement membrane of a tubule. Frequently, partial or 
complete degranulation of the intratubular eosinophils occurred. Degenerating and phagocytosed sperm débris was often present. The three types of tubule tended to occur in zones in any one section. It seemed possible that each zone represented one tubule sectioned repeatedly on its convoluted course and this was confirmed by serial sectioning. Testes showing this third pattern of damage were seen 14 to 30 days after the initial immunization. Most occurred early in this period, suggesting that a leucocytic invasion preceded the pattern of damage described as type (b).

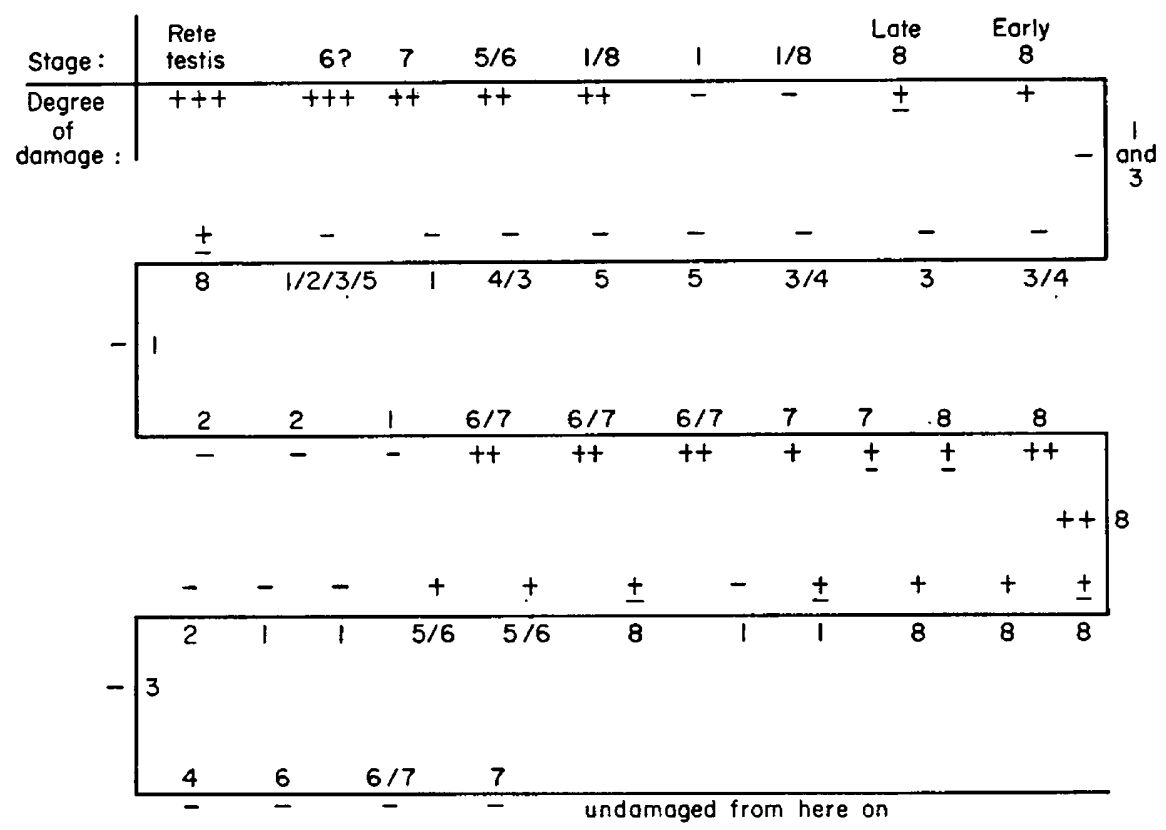

Text-fig. 1. Tabulation of tubule damage traced from the rete testis in serial sections of the same tubule.

In the inflamed testes, the vascular permeability to acriflavine was higher than usual but only the contents of the third type of tubule, in which cellular invasion was occurring, were stained with acriflavine (Pl. 1, Fig. 3). The weak, intratubular, nuclear fluorescence could readily be distinguished from the yellowish autofluorescent granules of negative control 1 . The nuclei of the contents and epithelium of the rete testis also stained vividly. The permeability rise must be short lived as the tubules in histological picture type (b) did not stain (see above), despite the absence of spermatogenesis. It is only in the tubules showing cellular invasion that any evidence of $\gamma$-globulin has been found, as judged by direct staining of sections with fluorescein-conjugated, anti-guineapig $\gamma$-globulin (Pl. 1, Figs. 6 and 7).

All animals in this group had immediate and delayed skin responses, and all possessed anaphylactic and cytotoxic antibodies. There was no correlation between the presence or titre of any one type of immune response and the degree of damage. 
The distribution of type (c) damage in testes

The evidence presented above suggests that damage is initiated at the rete testis. Serial sections of partially damaged testes showed that testicular inflammation and damage decreased in intensity in areas furthest from the rete. Individual tubules were traced through serial sections in one such partially damaged testis. In each section, the same tubule was scored for damage and for stage of spermatogenesis. A typical result is shown in Text-fig. 1. There is damage to stages 5 to 8 for the first part of the tubule but further from the rete testis, there is no damage to any stage. The stage sensitivity is probably related to the antigenic concentration on the germinal cells, for stages 5 to 8 contain the most mature spermatogenic cells and these are more susceptible to damage. The same pattern of decreasing damage in the parts of a tubule more remote from the rete was seen in all tubules examined. The length of individual tubules for which damage was present varied and did not obviously relate to interstitial inflammation. These results are highly suggestive of a spread of tubular damage following its initiation at the rete testis.

\section{DISCUSSION}

The results reported here suggest that antigen present in the rete testis and vasa efferentia is more vulnerable to immune attack than that in the seminiferous tubule. This finding partially confirms those of Waksman (1959). This greater vulnerability is understandable for the blood barrier at the rete testis is less effective than elsewhere in the testis (Waksman, 1960; Kormano, 1967, 1968) and phagocytosis of spermatozoa by intratubular macrophages first occurs in this part of the tract (Risley, 1963). Further evidence for a much greater vulnerability at the rete testis will be presented later (Johnson, 1970). The testis thus behaves as a closed duct system. As the immune response rises, it will have an initial effect at the rete testis. The damage here will predispose to testicular damage by secondarily boosting the immune response, and also by a local spread from the rete.

There is a slight increase in the acriflavine permeability of the invaded tubules, which also contain $\gamma$-globulin. The tubular barrier is not completely destroyed, for acriflavine staining is much weaker than that seen in the testis damaged by cadmium chloride (Johnson, 1969). The permeability increase might first occur due to a spread of interstitial inflammation from the rete and thus allow entry of free and cell-bound antibody. Alternatively, following entry of small amounts of antibody, the eosinophilic degranulation and release of acrosomal enzymes could make the tubule 'leaky'. Either process is likely to be autocatalytic leading to a spread of damage, and probably both occur.

The histological picture described for the early stages of damage indicates a massive leucocytic invasion and is similar to that described by Waksman (1959), though he failed to describe the marked presence of eosinophils. This finding is highly suggestive of damage by cellular immunity, but is an inconclusive piece of evidence taken in isolation. Macrophage involvement in nonspecific inflammatory lesions or following antigen-antibody interaction is frequent (Cohn, 1969). The eosinophilic invasion might also result from 
antigen-antibody complexing (Litt, 1963; Cohen, Sapp, Rizzo \& Kostage, 1964). The possibility that the tissue damage may be a manifestation of the Arthus phenomenon is probably excluded by the relative paucity of neutrophils. Many of the reports which fail to describe leucocytic involvement were of studies made too late to detect cellular invasion. The failure of Brown et al. (1967) to report cellular invasion in their sequential study from Day 0 to Day 14 is more puzzling. Examination of much of the data on the relationship between the type of immune response and the nature of the testicular damage suggests that either type of response, alone or jointly with the other, can induce damage if it is strong enough to breach the testicular barrier. Asherson (1967) has demonstrated that cellular and humoral factors potentiate each other when acting together, and induction of a dual response might therefore be expected to increase the incidence of testicular damage. This is in fact the case, as reported by Brown et al. (1967) and Voisin \& Toullet (1968).

Induction of testicular damage may be seen as dependent upon the immune response, of whatever type, overcoming the resistance presented by the testicular barrier. Once damage is initiated, the barrier becomes less effective. The use of adjuvant will increase the level of the immune response and may decrease the effectiveness of the barrier (Boughton \& Spector, 1963). The failure to correlate the degree of damage with any one type of immune response ceases to be a problem. The difficulty in transferring damage by serum or cellular transfusions becomes more readily understandable, for the transferred cells will need to multiply before becoming effective.

\section{ACKNOWLEDGMENTS}

The author would like to thank Dr R. G. Edwards for valuable discussion, and Miss S. Fawcitt and Miss V. Hunn for technical assistance. The work was supported by a Medical Research Council Scholarship and the Ford Foundation.

\section{REFERENCES}

Asherson, G. L. (1967) The passive transfer of delayed hypersensitivity in the guinea-pig. II. The ability of passively transferred antibody to cause local inflammation and retention of antigen and the role of these phenomena in the passive transfer of delayed hypersensitivity. Immunology, 13, 441.

Askonas, B. A. \& Rhodes, J. M. (1965a) Immunogenicity of antigen-containing ribonucleic acid preparations from macrophages. Nature, Lond. 205, 470.

Askonas, B. A. \& Rhodes, J. M. (1965b) Is antigen associated with macrophage RNA? In: Molecular and Cellular Basis of Antibody Formation, p. 503. Ed. J. Sterzl. Czechoslovak Academy of Sciences, Prague.

Bishop, D. W. (1961) Aspermatogenesis induced by testicular antigen uncombined with adjuvant. Proc. Soc. exp. Biol. Med. 107, 116.

Bishop, D. W. \& Carlson, G. L. (1965) Immunologically induced aspermatogenesis in guinea-pigs. Ann. N.Y. Acad. Sci. 124, 247.

Blogh, K. J., Kourilsky, F. N., Ovary, Z. \& Benagerraf, B. (1963) Properties of guinea-pig 7S antibodies. III. Identification of antibodies involved in complement fixation and haemolysis. F. exp. Med. 117, 965 .

Boughton, B. \& Spector, W. G. (1963) Autoimmune testicular lesions induced by injury to the contralateral testis and intradermal injection of adjuvant. 7. Path. Bact. 86, 69.

Brown, P. C., GlynN, L. E. \& Holborow, E. J. (1963) The pathogenesis of experimental allergic orchitis in guinea-pigs. 7. Path. Bact. 86, 505. 
Brown, P. C., Glynn, L. E. \& Holborow, E. J. (1967) The dual necessity for delayed hypersensitivity and circulating antibody in the pathogenesis of experimental allergic orchitis in guinea-pigs. Immunology, 13, 307.

Brown, P. C., Holborow, E. J. \& GLYN, L. E. (1965) The aspermatogenic antigen in experimental allergic orchitis in guinea-pigs. Immunology, 9, 255.

Chutna, J. \& Rychlikova, M. (1964) A study of the biological effectiveness of antibodies in the development and prevention of experimental autoimmune aspermatogenesis. Folia Biol. 10, 188.

Cohen, S. C., SApp, T. M., Rizzo, A. P. \& Kostage, S. T. (1964) Experimental eosinophilia VII. Lymph node responses to altered globulins. F. Allergy, 35, 346.

CoHs, Z. A. (1969) The structure and function of monocytes and macrophages. Adv. Immunol. 9, 163.

Freund, J., Lipton, M. M. \& Thompson, G. E. (1953) Aspermatogenesis in the guinea-pig induced by testicular tissue and adjuvant. 7 . exp. Med. 97, 711 .

FreUnd, J., Lipton, M. M. \& Thompson, G. E. (1955) Aspermatogenesis, anaphylaxis and cutaneous sensitisation induced in the guinea-pig by homologous testicular extract. $\mathcal{F}$. exp. Med. 101, 591 .

Johnson, M. H. (1969) The effect of cadmium chloride on the blood-testis barrier of the guinea-pig. 7. Reprod. Fert. 19, 551.

Johnson, M. H. (1970) An immunological barrier in the guinea-pig testis. F. Path. (In press).

Johnson, M. H. \& Setchell, B. P. (1968) Protein and immunoglobulin content of rete testis fluid of rams. F. Reprod. Fert. 17, 403.

Jonas, W. E., Gurner, B. W., Nelson, D. S. \& Coombs, R. R. A. (1965) Passive sensitisation of tissue cells. Int. Archs Allergy appl. Immun. 28, 86.

Katsh, S. \& Katsh, G. F. (1961) Antigenicity of spermatozoa. Fert. Steril. 12, 522.

Kormano, M. (1967) Dye permeability and alkaline phosphatase activity of testicular capillaries in the postnatal rat. Histochemie, 9, 327.

Kormano, M. (1968) Penetration of intravenous trypan blue into the rat testis and epididymis. Acta histochem. 30, 133.

Laurence, K. A. (1962) Immunologically induced aspermatogenesis. In: Proceedings of a Conference on Immuno-reproduction, p. 29. Population Council.

LrrT, M. (1963) Studies on experimental eosinophilia. V. Eosinophils in lymph nodes of guinea-pigs following primary antigenic stimulation. Am. F. Path. 42, 529.

PAterson, P. Y. (1966) Experimental allergic encephalomyelitis and autoimmune disease. Adv. Immunol. $5,131$.

Risley, P. L. (1963) Physiology of the male accessory organs. In: Mechanisms Concerned with Conception. Ed. C. G. Hartman. Pergamon Press, Oxford.

SaINTE-MARIE, G. (1962) A paraffin embedding technique for studies employing immunofluorescence. 7. Histochem. Cytochem. 10, 250.

Stone, S. M., Lerner, E. M. \& GoOde, J. M. (1968) Adoptive transfer of autoimmune aspermatogenesis in inbred guinea-pigs. Fedn Proc. Fedn Am. Socs exp. Biol. 27, 363.

Toullet, F. (1965) Recherches sur la nature et les propriétés immunologiques des autoantigènes de spermatozoides de cobaye. Thèse de Sciences, Paris.

Voisin, G. A. \& Tourlet, F. (1968) Etude sur l'orchite aspermatogénétique autoimmune et les autoantigènes de spermatozoides chez le cobaye. Annls Inst. Pasteur, Paris, 114, 727.

Voisin, G. A., Toullet, F. \& Maurer, P. (1958) The nature of tissular antigens with particular reference to autosensitisation and transplantation immunity. Ann. N.Y. Acad. Sci. 73, 726.

Waksman, B. H. (1959) A histologic study of the auto-allergic testis lesion in the guinea-pig. F. exp. Med. 109, 311.

Waksman, B. H. (1960) The distribution of experimental auto-allergic lesions. Its relation to the distribution of small veins. Am. 7. Path. 37, 673 . 